\title{
Influence of sex, age and smoking status on patient comfort during gastroscopy with pharyngeal anesthesia by a new benzocaine-tetracaine preparation
}

André L Gelly MD FRCP ${ }^{1}$, Alain Farley MD FRCP ${ }^{2}$, Judy Boyer CGRN ${ }^{3}$, Michelle Asselin BA ${ }^{2}$, Jean Spénard PhD ${ }^{3}$

\begin{abstract}
AL Gelly, A Farley, J Boyer, M Asselin, J Spénard. Influence of sex, age and smoking status on patient comfort during gastroscopy with pharyngeal anaesthesia by a new benzocainetetracaine preparation. Can J Gastroenterol 1998;12(6):431433. Thirty-seven patients underwent gastroscopy under pharyngeal anaesthesia with benzocaine-tetracaine (Endospray; Axcan Pharma). Patients recorded their perception of intubation, of the rest of the procedure, of taste and of throat well-being on visual analogue scales. Throat well-being and taste scores were better for men than for women. There was a strong trend for smokers to be more intolerant to intubation than nonsmokers. There was a weak but significant correlation for younger patients to be more intolerant to intubation. This study points to age and smoking status as possible factors influencing the perception of gastroscopy under pharyngeal anesthesia.
\end{abstract}

Key Words: Age, Anesthesia, Gastroscopy, Pharyngeal, Smoking
Influence du sexe, de l'âge et du tabagisme sur le confort des patients lors de gastroscopies avec anesthésie pharyngée au moyen d'une nouvelle préparation de benzocaïne-tétracaïne

RÉSUMÉ : Trente-sept patients ont subi une gastroscopie sous anesthésie pharyngée au moyen de benzocaïne-tétracaïne (Endospray; Axcan Pharma). Les patients ont consigné leurs perceptions de l'intubation, du reste de l'intervention, du goût et de la sensation au niveau de la gorge au moyen d'échelles analogiques visuelles. Les résultats enregistrés pour les sensations au niveau de la gorge et pour le goût ont été meilleurs pour les hommes que pour les femmes. Les fumeurs ont tendu fortement à moins bien tolérer l'intubation que les non-fumeurs. On a noté une corrélation faible, mais significative, entre le jeune âge des patients et une relative intolérance à l'intubation. Cette étude permet de rappeler que l'âge et le tabagisme sont des facteurs qui peuvent influer sur la perception de la gastroscopie sous anesthésie pharyngée.
G astroscopic examination is a procedure usually perceived as mildly or extremely unpleasant by patients. Even if upper gastrointestinal endoscopy can be performed without premedication (1), many studies have shown the benefits of pharyngeal anesthesia, either alone or in combination with systemic medication, to minimize patient dis- comfort (2-8). Although gastroscopy is a very common procedure, published data on factors influencing the patients' level of comfort are very rare.

This study explored the influence of some variables on patients' sensation of discomfort during standard gastroscopy under pharyngeal anesthesia without systemic sedation.

${ }^{1}$ Centre Hospitalier Anna Laberge, Chateauguay; ${ }^{2}$ Centre De Gastro-Entérologie et d'Endoscopie de Montréal, Montréal; ${ }^{3}$ Axcan Pharma Inc, St-Hilaire and Departement de Pharmacologie, Faculté de Médecine, Université de Montréal, Montréal, Québec

Correspondence and reprints: Dr Jean Spénard, Axcan Pharma, 597 boul Laurier, Saint-Hilaire, Québec J3H 6C4. Telephone 450-467-5138, fax 450-467-5857, e-mail jspenard@axcan.com

Received for publication October 27, 1997. Accepted July 8, 1998 
TABLE 1

Mean demographics and results from patients

\begin{tabular}{|c|c|c|c|c|c|}
\hline Variable & $\begin{array}{l}\text { Mean for } \\
\text { women }\end{array}$ & $\begin{array}{c}\text { Range for } \\
\text { women }\end{array}$ & $\begin{array}{l}\text { Mean for } \\
\text { men }\end{array}$ & $\begin{array}{c}\text { Range } \\
\text { for men }\end{array}$ & $\mathbf{P}$ \\
\hline Age (years) & 56.7 & $38-75$ & 50.0 & $20-76$ & \\
\hline Height $(\mathrm{cm})$ & 157 & $148-173$ & 176 & 168-208 & \\
\hline Weight (kg) & 70.6 & $42-100$ & 80.6 & $50-143$ & \\
\hline $\begin{array}{l}\text { Previous } \\
\quad \text { gastroscopy }\end{array}$ & $\begin{array}{r}\text { yes: } n=8 \\
\text { no: } n=9\end{array}$ & & $\begin{array}{c}\text { yes: } n=11 \\
\text { no: } n=9\end{array}$ & & \\
\hline Smoking status & $\begin{array}{l}\text { yes: } n=2 \\
\text { no: } n=15\end{array}$ & & $\begin{array}{l}\text { yes: } n=7 \\
\text { no: } n=13\end{array}$ & & \\
\hline $\begin{array}{l}\text { Score for } \\
\quad \text { intubation }\end{array}$ & 79.9 & $0-100$ & 67.6 & $0-100$ & 0.212 \\
\hline $\begin{array}{l}\text { Score for rest of } \\
\text { procedure }\end{array}$ & 67.7 & $0-100$ & 72.4 & $14-100$ & 0.628 \\
\hline $\begin{array}{c}\text { Score for throat } \\
\text { well-being }\end{array}$ & 72.2 & $0-100$ & 91.7 & $67-100$ & 0.040 \\
\hline Score for taste & 71.3 & $7-100$ & 85.3 & $46-100$ & 0.042 \\
\hline
\end{tabular}

\section{PATIENTS AND METHODS}

For three consecutive weeks, patients presenting for upper gastrointestinal endoscopy were asked to participate in this open-label, two-site, cohort trial. The primary objective of the trial was to evaluate the acceptability of a new flavoured pharyngeal anesthetic preparation of benzocaine and tetracaine (Endospray, Axcan Pharma) for endoscopic procedures. Exploratory analysis on the relationship between age, sex, previous gastroscopy, smoking status and patients' score is presented below.

During standard gastroscopy, investigators used their judgement to select the amount of local anesthetic necessary to induce a satisfactory local anesthesia. No systemic medication was used. After the gastroscopy, the patient rested a few minutes and then filled out a questionnaire about sensation of discomfort during intubation, sensation of discomfort during the rest of the procedure, rating of the well-being of his/her throat and rating of the taste. All items were evaluated on a visual analogue scale from 0 to $100 \mathrm{~mm}$. A score of 0 meant an "unbearable sensation", while 100 meant "no pain at all" for the first three parameters. A score of 0 meant "very bad taste" and 100 meant "very good taste" for the fourth parameter. Endoscopists and assistants also rated their evaluation of the ease of intubation and of the rest of the procedure on a similar visual analogue scale.

To qualify for inclusion in the study, patients had to be between 18 and 75 years old and to sign an informed consent. Known sensitivity to local anesthetics or to one of the other ingredients of Endospray (alcohol, mint, etc), pregnancy, mental impairment, cardiac condition or throat lesion were exclusion criteria.

Descriptive statistics were calculated. Student's $t$ test was used to seek differences in scores between study sites, between patients who had had a previous upper gastrointestinal endoscopy and those who had never had one, between men and women, and between smokers and nonsmokers.

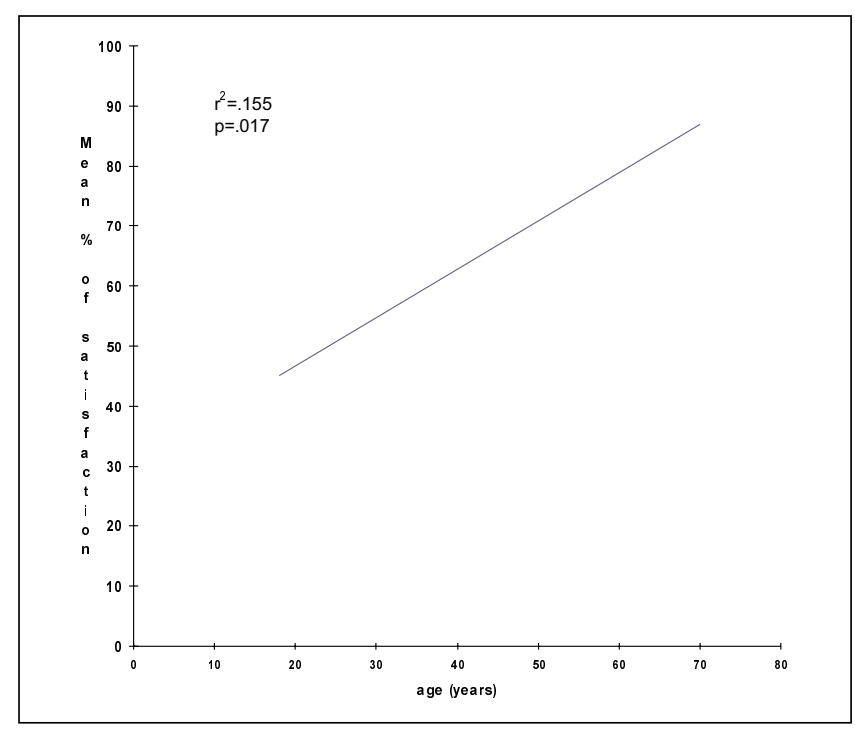

Figure 1) Relationship between mean percentage of satisfaction and patients' age

The influence of patient age on scores was determined by linear regression techniques.

\section{RESULTS}

Thirty-seven patients, 20 men and 17 women, were included. Their demographics and mean scores of sensations are presented in Table 1. Endoscopists rated mean \pm SD scores of $86.9 \pm 1.9$ for ease of intubation and $85.7 \pm 2.1$ for ease of the rest of the procedure. Assistants rated mean \pm SD scores of $83.3 \pm 3.5$ for ease of intubation and $86.4 \pm 2.8$ for ease of the rest of the procedure.

There were no statistically significant differences in scores between the two study sites for any of the four parameters assessed. There were no statistically significant differences between patients' scores for those who had previously had a gastroscopy and for those who had not for any of the four parameters assessed.

There was a statistically significant difference between men and women for rating of throat well-being $(\mathrm{P}=0.040)$ and taste $(\mathrm{P}=0.042)$, but not for tolerance to discomfort during intubation $(\mathrm{P}=0.212)$ or for the rest of the procedure $(\mathrm{P}=0.628)$.

There was a strong trend for smokers to rate a lower score for tolerance to discomfort during intubation than nonsmokers (58.5 versus 78.0, respectively, $\mathrm{P}=0.086$ ), but not for the rest of the procedure $(\mathrm{P}=0.470)$, throat well-being $(\mathrm{P}=0.239)$ or taste $(\mathrm{P}=0.760)$. There were 19 nonsmokers and one smoker in site 1 , and nine nonsmokers and eight smokers in site 2. If one considers only site 2 , where the distribution is more homogenous, the trend for tolerance to discomfort during intubation become a highly significant difference ( 54 versus $89, \mathrm{P}=0.016$ ).

There was a weak $\left(\mathrm{r}^{2}=0.155\right)$ but statistically significant $(\mathrm{P}=0.017)$ correlation between patients' age and score for tolerance to discomfort during intubation (Figure 1) but not for the rest of the procedure $(\mathrm{P}=0.442)$, throat well-being $(\mathrm{P}=0.743)$ or taste $(\mathrm{P}=0.228)$. 


\section{DISCUSSION AND CONCLUSION}

This study points to sex, age and smoking status as variables that may influence the sensation of comfort felt by patients during gastroscopy. These findings confirm previous observations on the influence of age made by Froehlich et al (4) and Mulcahy et al (3). The influence of smoking status, however, does not seem to be documented in the literature. Although this analysis was only exploratory and based on a small sample size, the very small $\mathrm{P}$ values associated with these results suggest a strong influence of age and smoking.

Although Froehlich et al (4) found a statistically significant difference in tolerance scores between men and women, we did not, but this lack of significance may be related to insufficient statistical power given the small number of patients in each group and the $\mathrm{P}$ value close to 0.05 . Confirmation of these findings is required by a well-designed study, with sufficient sample size to provide enough power and to allow isolation of confounding factors. The present trial was a pilot one, and calculations were done on an exploratory basis only.

This study also shows an overall good acceptability profile of this new benzocaine-tetracaine preparation by patients, endoscopists and assistants.

\section{REFERENCES}

1. Al-Atrakchi HA. Upper gastrointestinal endoscopy without sedation: a prospective study of 2000 examinations. Gastrointest Endosc 1989;35:79-81.

2. Campo R, Brullet E, Montserrat A, Calvet X, Rivero E, Broton C. Topical pharyngeal anesthesia improves tolerance of upper gastrointestinal endoscopy: a randomized double-blind study. Endoscopy 1995;27:659-64.

3. Mulcahy HE, Greaves RR, Ballinger A, et al. A double-blind randomized trial of low-dose versus high-dose topical anaesthesia in unsedated upper gastrointestinal endoscopy. Aliment Pharmacol Ther 1996;10:975-9.

4. Froehlich F, Schwizer W, Thorens J, Köhler M, Gonvers JJ, Fried M. Conscious sedation for gastroscopy: patient tolerance and cardiorespiratory parameters. Gastroenterology 1995;108:697-704.

5. Hedenbro JL, Ekelund M, Jansson O, Lindblom A. A randomized, double-blind, placebo-controlled study to evaluate topical anaesthesia of the pharynx in upper gastrointestinal endoscopy. Endoscopy 1992;24:585-7.

6. Jameson JS, Kapadia SA, Polson RJ, McCarthy PT, Misiewicz JJ. Is oropharyngeal anaesthesia with topical lignocaine useful in upper gastrointestinal endoscopy? Aliment Pharmacol Ther 1992;6:739-44.

7. Leitch DG, Wicks J, el Beshir OA, Ali SA, Chaudhury BK. Topical anesthesia with $50 \mathrm{mg}$ of lidocaine spray facilitates upper gastrointestinal endoscopy. Gastrointest Endosc 1993;39:384-7.

8. Gordon MJ, Mayes GR, Meyer GW. Topical lidocaine in preendoscopic medication. Gastroenterology 1976;71:564-9. 


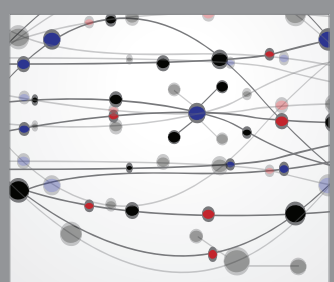

The Scientific World Journal
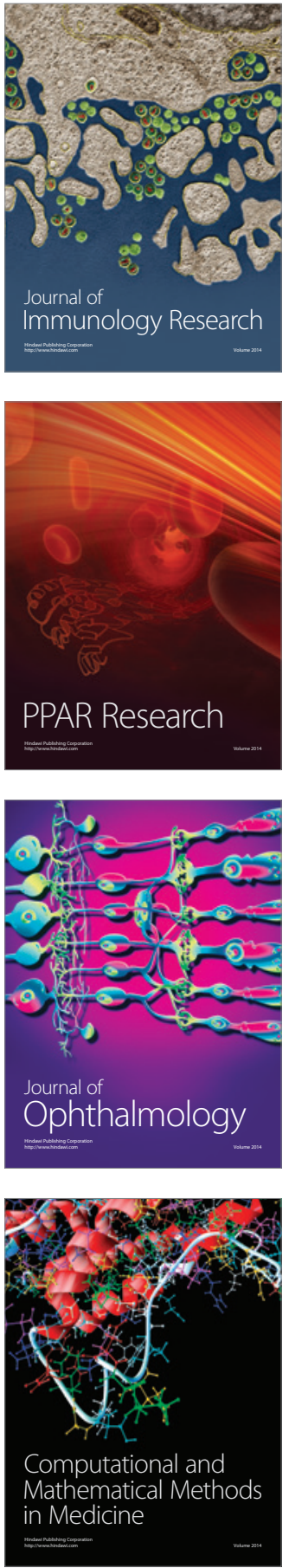

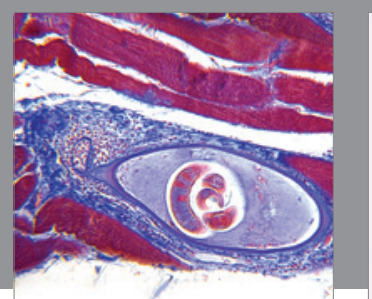

Gastroenterology Research and Practice

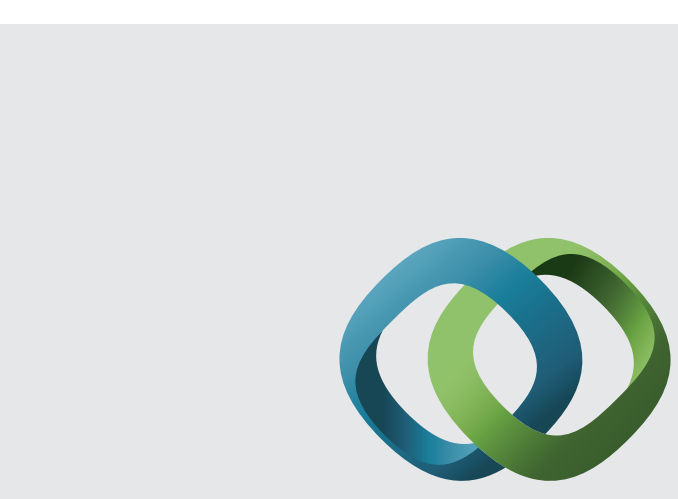

\section{Hindawi}

Submit your manuscripts at

http://www.hindawi.com
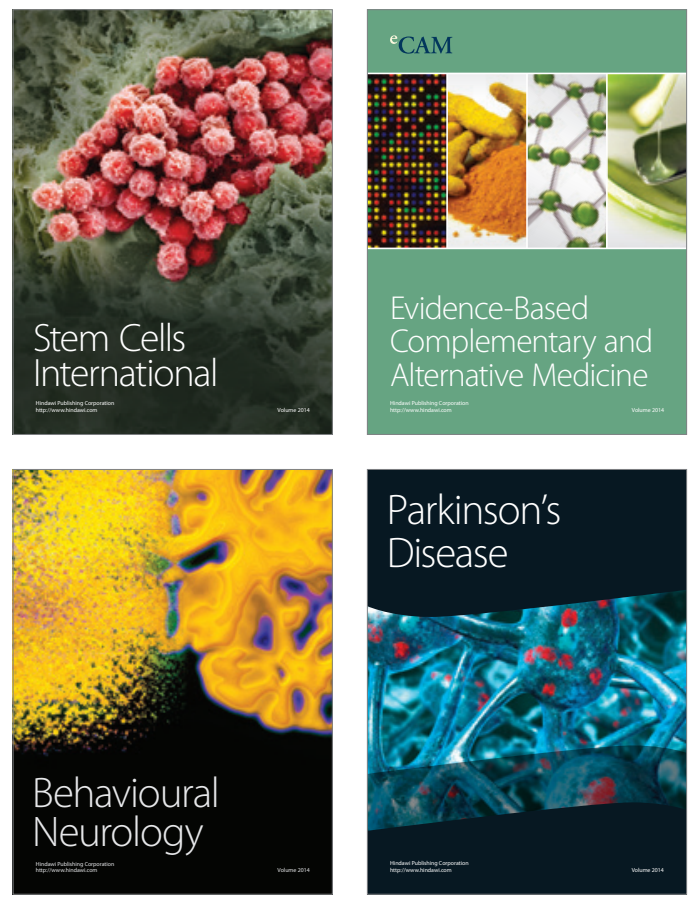
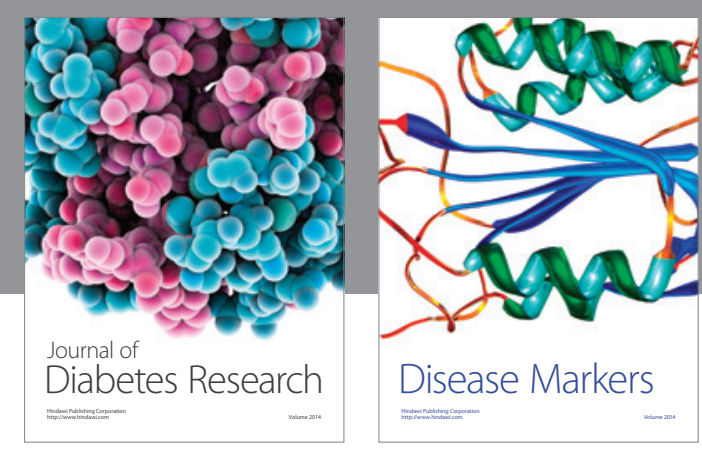

Disease Markers
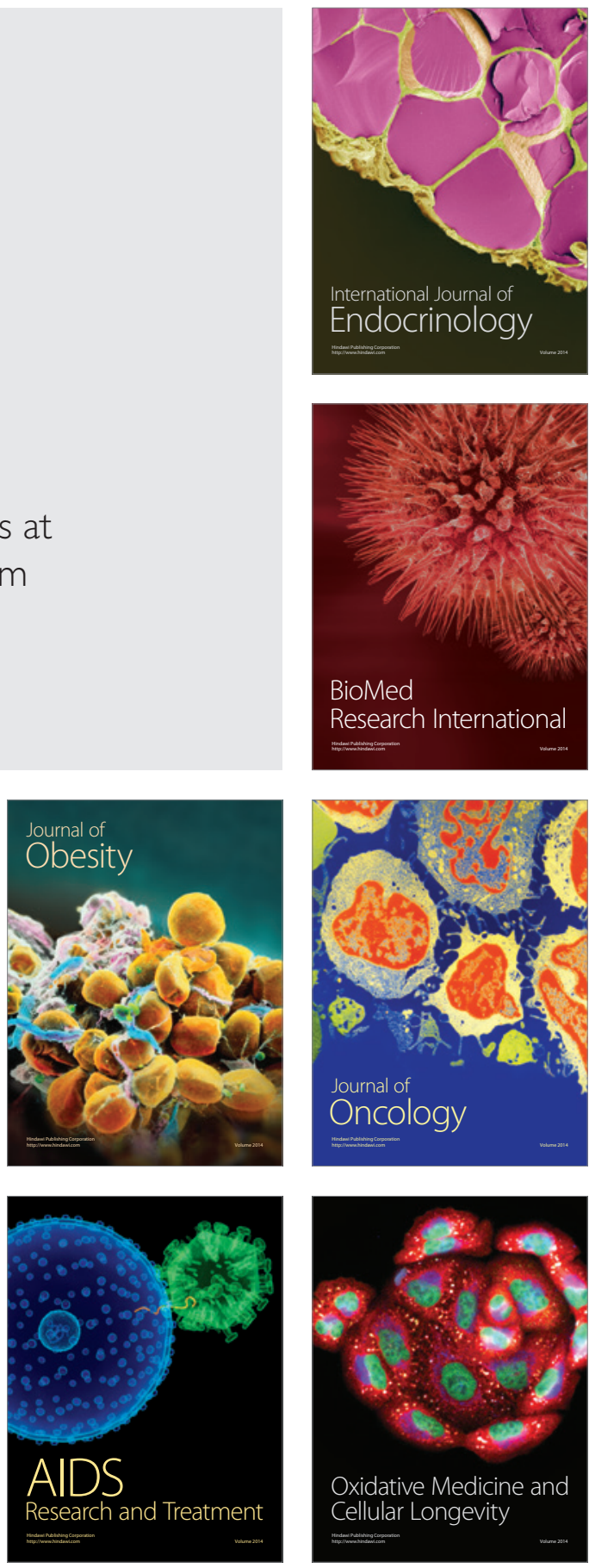